\title{
Inhibition of Experimental Lung Inflammation and Bronchitis by Phytoformula Containing Broussonetia papyrifera and Lonicera japonica
}

\author{
Hyun Jeong Ko ${ }^{1}$, Jeong Ho Jin ${ }^{1}$, Oh Song Kwon ${ }^{1}$, Jong Taek Kim², Kun Ho Son ${ }^{3}$ and Hyun Pyo Kim ${ }^{1, *}$ \\ ${ }^{1}$ College of Pharmacy, ${ }^{2}$ College of Veteniary Medicine, Kangwon National University, Chuncheon 200-701, \\ ${ }^{3}$ Deparment Food and Nutrition, Andong National University, Andong 760-749, Republic of Korea
}

\begin{abstract}
Broussonetia papyrifera and Lonicera japonica have long been used in the treatment of inflammatory disorders, especially respiratory inflammation, in Chinese medicine. Previously, phytoformula (BL) containing B. papyrifera and $L$. japonica was found to exert strong anti-inflammatory activity in vitro and in vivo. In this study, the effects of BL on lung inflammation including bronchitis were examined in vitro and in vivo. BL $(10-100 \mu \mathrm{g} / \mathrm{ml})$ inhibited nitric oxide (NO) production of lipopolysaccharide (LPS)-treated alveolar macrophages, MH-S cells, primarily by down-regulating inducible NO synthase. BL also inhibited production of the proinflammatory cytokines, TNF- $\alpha$ and IL-6. Against an animal model of pleural cavity inflammation, BL (200-400 mg/kg) significantly inhibited $5 \mathrm{~h}$ and $24 \mathrm{~h}$ carrageenan-induced pleurisy in rats when administered orally. Additionally, BL inhibited experimental bronchitis induced by intratracheal instillation of LPS to rats. Taken together, these results indicate that BL may be effective for the treatment of human lung inflammation as well as bronchitis.
\end{abstract}

Key Words: Broussonetia papyrifera, Lonicera japonica, Lung inflammation, Bronchitis

\section{INTRODUCTION}

Many patients suffer from lung inflammatory disorders including asthma, bronchitis and chronic obstructive pulmonary disorders (COPD). Several classes of drugs including bronchodilators, antitussives, steroids and leukotriene (LT) receptor antagonists have been used to treat these disorders. However, these drugs sometimes do not provide fundamental care, even though the major symptoms are alleviated (Jeffery, 2001). Thus, new effective drugs with novel action mechanism(s) are needed to treat lung inflammatory disorders. In this regard, natural products may be applied safely for treating human lung inflammation and bronchitis.

The root barks of Broussonetia papyrifera (L.) Vent. (Moraceae) distributed in China, Japan and Korea have been used as anti-inflammatory and antitussive agents in traditional Chinese medicine, especially for the treatment of older people having bronchitis (Editorial Committee, 1999). Recently, the $95 \%$ ethanol extracts of the radix, stems, leaves and fruits of B. papyrifera showed antinociceptive and anti-inflammatory activity in vivo, with radix having the strongest activity (Lin et al., 2008). Lonicera japonica (Thunb.) (Caprifoliaceae) is a

www.biomolther.org

Open Access DOI: 10.4062/biomolther.2011.19.3.324

pISSN: 1976-9148 elSSN: 2005-4483

Copyright $\odot 2011$ The Korean Society of Applied Pharmacology twining shrub that has long been used to treat urinary disorders, fevers, and headache (Shougakukan, 1985). Additionally, the whole plant of $L$. japonica, which is widely distributed widely in China and Korea, has frequently been used as an anti-inflammatory agent, especially for the treatment of respiratory tract inflammation (Lee et al., 1998). Recently, it was also reported that highly purified fraction showed potent antiinflammatory and analgesic activities (Ryu et al., 2010). It has previously been reported that a 1:1 (w/w) mixture $(B L)$ of the ethylacetate fraction from the root barks of $B$. papyrifera and the $70 \%$ aqueous ethanol extract from the whole plants of $L$. japonica exerted significant and considerable anti-inflammatory activity in vitro and in vivo (Jin et al., 2010). BL exerted anti-inflammatory activity against $\lambda$-carrageenan-induced paw edema and arachidonic acid-induced ear edema. Moreover, $\mathrm{BL}$ also showed analgesic activity. The cellular mechanisms of these anti-inflammatory activities of BL include 5-lipoxygenase (5-LOX) inhibition and inhibition of proinflammatory enzyme induction such as inducible nitric oxide synthase (iNOS).

In the present study, inhibitory effects of BL against experimental lung inflammation and bronchitis were examined to establish its potential for use as a new therapeutic agent against

Received Apr 18, 2011 Revised Jun 13, 2011 Accepted Jun 13, 2011

\section{*Corresponding Author}

E-mail: hpkim@kangwon.ac.kr

Tel: +82-33-250-6915, Fax: +82-33-255-7865 
lung inflammatory disorders, especially for treating bronchitis.

\section{MATERIALS AND METHODS}

\section{Chemicals}

2-Amino-5,6-dihydro-6-methyl-4H-1,3-thiazine hydrochloride (AMT) was purchased from Tocris Cookson Ltd. (UK). 3-(4,5-Dimethylthiazol-2-yl)-2,5-diphenyltetrazolium bromide (MTT), indomethacin, prednisolone, $\lambda$-carrageenan (CGN) and LPS (Escherichia coli 0127:B8) were purchased from Sigma Chem. (St. Louis, MO). Zileuton (5-LOX inhibitor) and montelukast (LT receptor antagonist) were purchased from Tocris Bioscience and Hwail Pharm. Co., Ltd. DMEM and other cell culture reagents including FBS were products of Gibco BRL (Grand Island, NY). Protein assay kit was purchased from Bio-Rad Lab. (Hercules, CA).

\section{Animals}

Male Sprague-Dawley (SD) rats (4 weeks old, specific pathogen-free) were obtained from Orient-Bio Ltd. (Korea). Animals were fed with standard lab. chow and water ad libitum. The animals were maintained in an animal facility (KNU) at $20-22^{\circ} \mathrm{C}$ under $40-60 \%$ relative humidity and a $12 \mathrm{~h} / 12 \mathrm{~h}$ (light/dark) cycle for at least 7 days prior to the experiment. The experimental design using the animals was approved by the local committee for animal experimentation, KNU (KIA-
CUC-09-0012). In addition, the ethical guidelines described in the KFDA Guide for the Care and Use of Laboratory Animals were followed throughout the experiments.

\section{Plant materials}

B. papyrifera collected in southern China were obtained from Songlim Pharm. Co., Ltd. (Seoul, Korea) and the plant materials were authenticated by one of the authors, Dr. K. H. Son (Andong National University, Korea) and a voucher specimen was deposited in Andong National University. The dried root barks of $B$. papyrifera were chopped and extracted with ethanol. The ethanol extract was partitioned with ethylacetate and water. The ethylacetate fraction was then dried under vacuum and this dried fraction was used to prepare $B L$ as below. The final yield of this ethylacetate fraction in one typical extraction and fractionation procedure was $7.77 \%(\mathrm{w} / \mathrm{w})$. The major constituents, papayriflavonol $\mathrm{A}$ and broussochalcone $A$, were isolated according to the previously published procedures (Son et al., 2001). For determination of the contents of major constituents, HPLC analysis was carried out. Alliance VWD separation module (Waters) and Inertsil ODS4 column $(4.6 \times 150 \mathrm{~mm}, 5 \mu \mathrm{m})$ were employed using the mobile phase of tetrahydrofuran:water, $\mathrm{pH} 3.0$ (47:53). The flow rate was 0.6 $\mathrm{ml} / \mathrm{min}$ and the peaks were detected at UV $390 \mathrm{~nm}$. From the HPLC analysis, papyriflavonol A and broussochalcone A were found to be $1.35 \%$ and $2.58 \%(\mathrm{w} / \mathrm{w})$, respectively as shown in Fig. 1.

(a)

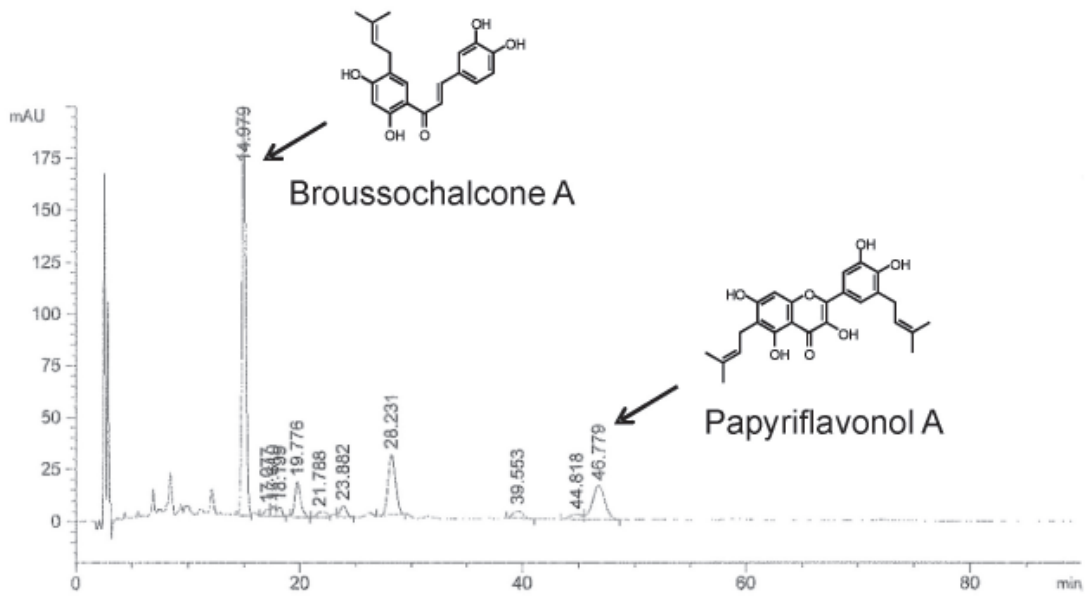

(b)

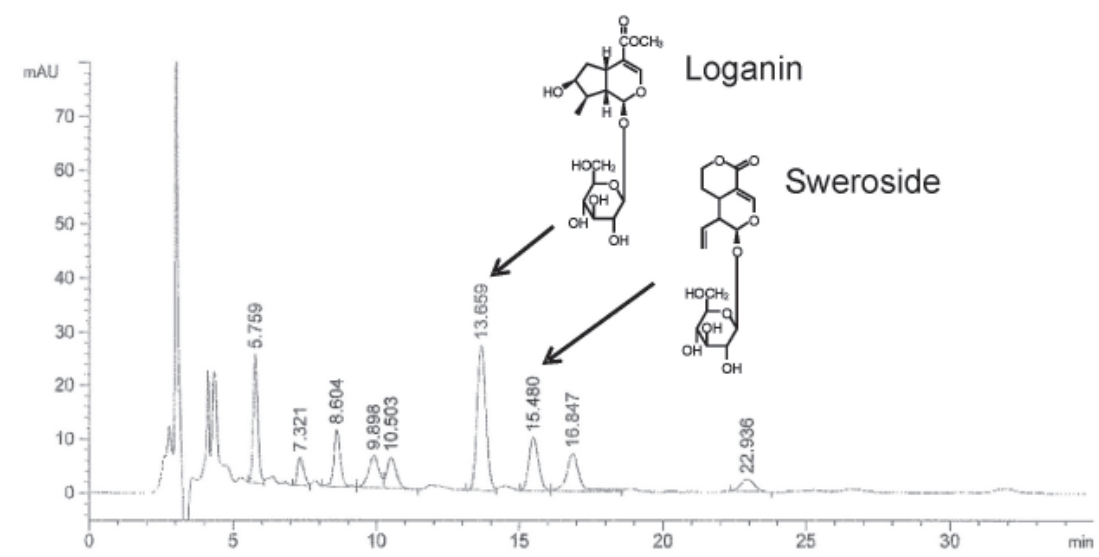

Fig. 1. Chemical structures of the major constituents in B. papyrifera and $L$. japonica and HPLC analysis of the extracts. (a) HPLC chromatogram of $B$. papyrifera, (b) HPLC chromatogram of L. japonica. All HPLC analytical conditions were described in Materials and methods. 
L. japonica cultivated in southern China was purchased from Songlim Pharm. Co., Ltd. and this plant material was authenticated by Dr. K. H. Son and a voucher specimen was deposited in Andong National University. The dried whole plant was then chopped and extracted with $70 \%$ aqueous ethanol. The ethanol extract was then dried under vacuum and this dried extract was used to prepare BL. The yield of the ethanol extract in one typical extraction procedure was $9.74 \%$ $(\mathrm{w} / \mathrm{w})$. The major constituents, loganin and sweroside, were isolated as previously described (Kawai et al., 1988). HPLC analysis using the mobile phase of acetonitrile:water, $\mathrm{pH} 3.0$ $(13: 87)$ was performed. The flow rate was $0.6 \mathrm{ml} / \mathrm{min}$ and the peaks were detected at UV $239 \mathrm{~nm}$. In this extract, loganin and sweroside were found to be $4.19 \%$ and $3.30 \%$, respectively. $B L$ is a $(1: 1, w / w)$ mixture of the ethylacetate fraction of $B$. papyrifera and the ethanol extract of $L$. japonica and used throughout this study.

\section{MH-S cell culture and measurement of nitric oxide (NO), TNF- $\alpha$ and IL-6}

$\mathrm{MH}-\mathrm{S}$ cells, a mouse alveolar macrophage cell line, obtained from American type culture collection (ATCC, Rockville, VA) were cultured with DMEM supplemented with $10 \%$ FBS and $1 \%$ antibiotics $(100 \mathrm{U} / \mathrm{ml}$ penicillin and $100 \mu \mathrm{g} / \mathrm{ml}$ streptomycin) in a $5 \% \mathrm{CO}_{2}$ atmosphere at $37^{\circ} \mathrm{C}$. The cells were activated with lipopolysaccharide (LPS) as previously described (Chi et al., 2001a). Briefly, cells were plated in 96-well plates $\left(2 \times 10^{5}\right.$ cells/well). After pre-incubation for $2 \mathrm{~h}$, test compounds and LPS $(1 \mathrm{mg} / \mathrm{ml})$ were added and incubated for $24 \mathrm{~h}$ unless otherwise specified. Media was collected and NO, TNF- $\alpha$ and IL-6 concentrations were determined. To assess NO production, the stable conversion product of $\mathrm{NO}$, nitrite $\left(\mathrm{NO}_{2}^{-}\right)$, was measured using Griess reagent and the optical density was determined at $550 \mathrm{~nm}$. The concentrations of TNF- $\alpha$ and IL-6 were measured using ELISA kit (Assay Design Inc.) according to the manufacturer's recommendation. The cell viability was checked using an MTT bioassay as previously described (Mossman, 1983). At all concentrations tested, BL and AMT did not show cytotoxic effect on MH-S cells.

\section{Western blot analysis}

To measure the protein level of inducible NO synthase (iNOS), Western blotting technique was used (Chi et al., 2001a). MH-S cells were cultured in 6 -well plates $\left(5 \times 10^{6}\right.$ cells/ well) in the presence or absence of LPS $(1 \mu \mathrm{g} / \mathrm{ml})$ with/without test compounds for 16-20 h. After cell homogenates were prepared, the supernatant was obtained by centrifugation at $15,000 \mathrm{~g}$ for $30 \mathrm{~min}$. Using Tris-glycine gels (8\%), electrophoresis was carried out and bands were blotted to PVDF membranes. The membranes were incubated with iNOS antibody (N32030, Transduction Lab.) and the bands were visualized by chemiluminescent reagent (Amersham, UK).

\section{CGN-induced pleurisy}

According to the procedure of Schrier et al. (1990), $0.2 \mathrm{ml}$ of $1 \%$ CGN solution in sterile saline was injected intrapleurally to rats. The test compounds were orally administered 1 $\mathrm{h}$ prior CGN injection. The animals were sacrificed 5 or $24 \mathrm{~h}$ after CGN injection. The chest was opened by lateral incision. DMEM (3 ml) with 10\% FCS was injected into pleural cavity and pleural fluid was aspirated using Pasteur pipette. This washing procedure was repeated again and exudates were combined. After the volumes of pleural exudates were recorded, cell pellets were obtained by centrifugation at $200 \mathrm{~g}$ for 5 min. Total cell numbers were counted after RBCs were lysed with hemolytic solution $\left(0.85 \% \mathrm{NH}_{4} \mathrm{Cl}, 0.1 \mathrm{M}\right.$ Hepes$)$.

\section{Bronchitis induced by LPS instillation}

For inducing bronchitis, the modified method of Starcher and Williams (1989) was employed. For intratracheal instillation, rats were anesthetized by tribromoethanol and LPS ( $E$. coli $0127: B 8,2 \mathrm{mg} / \mathrm{ml}$ saline) was instilled directly to lung (100 $\mu \mathrm{l} / \mathrm{rat}$ ), using a microsprayer (Intratracheal aerosolizer, PennCentury, Inc., USA). Rats were maintained in up-right position at least for $5 \mathrm{~min}$. Sixteen hours later after LPS instillation, the animals were sacrificed and bronchoalveolar lavage fluid (BALF) was collected via intratracheal cannulation after $200 \mu \mathrm{l}$ infusion of saline. BALF collected were approximately $150 \mu \mathrm{l} /$ rat. For histology and other biochemical analysis, lungs were excised. Test compounds including BL were administered one hour prior to LPS instillation. For measuring proinflammatory cytokine concentration, reverse transcription-polymerase chain reaction (RT-PCR) analysis was carried out. In brief, total RNA was extracted using TRIzol (Invitrogen, Carlsbad, CA) from lung tissue and cDNA was synthesized by Superscript II reverse transcriptase with oligo (dT) primer (Invitrogen). The forward and reverse primers used for PCR amplification of IL$1 \beta$ and GAPDH from the lung of rats were as follows: IL-1 $\beta$ forward, 5'-GCA GCT ATG GCA ACT GTC C-3', and IL-1 $\beta$ reverse, 5'-GGT CAG ACA GCA CGA GGC-3', which amplified a 420 base pair sequence; COX-2 forward, 5'-GCA AAT CCT TGC TGT TCC AAT C-3', and COX-2 reverse, 5'-GGA GAA GGC TTC CCA GCT TTT G-3', which amplified a 335 base pair sequence, and GAPDH forward, 5'-GCC ATC AAC GAC CCC TTC AT-3', and GAPDH reverse, 5'-CGC CTG CTT CAC CAC CTT CT-3', which amplified a 702 base pair sequence of rat GAPDH. RT-PCR was performed using the MyCycler Thermal Cycler (Bio-Rad Lab., UK) and thermal cycler conditions were as follows: denaturation, annealing, and extension at 98 , 55 , and $72^{\circ} \mathrm{C}$ for $10 \mathrm{sec}, 30 \mathrm{sec}$, and $1 \mathrm{~min}$, respectively, for 30 cycles using Ex Taq (TaKaRa, Shiga, Japan). PCR products were electrophoresed on $1.2 \%$ agarose gel containing ethidium bromide and visualized using Gel Doc system (BioRad Lab.).

\section{Statistical analysis}

Experimental values were represented as arithmetic mean \pm SD. One way ANOVA followed by Dunnett's test was used to determine the statistical significance.

\section{RESULTS}

\section{In vitro study}

Macrophages induce iNOS when stimulated with LPS. LPS treatment $(1 \mu \mathrm{g} / \mathrm{ml})$ of $\mathrm{MH}-\mathrm{S}$ cells produced high amounts of $\mathrm{NO}$ as well as the proinflammatory cytokines, TNF- $\alpha$ and IL6. After $24 \mathrm{~h}$ of incubation, a significant amount of NO was produced $(27.9 \pm 1.2 \mu \mathrm{M})$ over the basal level of $2.7 \pm 0.1 \mu \mathrm{M}$ $(n=3)$. Under this condition, BL reduced NO production in a concentration-dependent manner at 10-100 $\mu \mathrm{g} / \mathrm{ml}$ (Fig. 2a). The $I_{50}$ value was calculated to be $102.5 \mu \mathrm{g} / \mathrm{ml}$. The reference compound, AMT (NOS inhibitor), potently inhibited NO production $(59.3 \%$ at $1 \mu \mathrm{M})$. BL also reduced TNF- $\alpha$ and IL-6 
Ko et al. Inhibition of B. papyrifera and L. japonica on Bronchitis

(a)

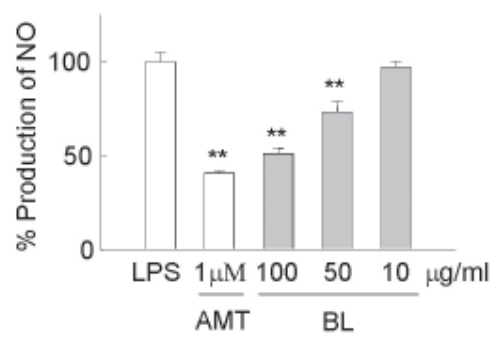

(c)

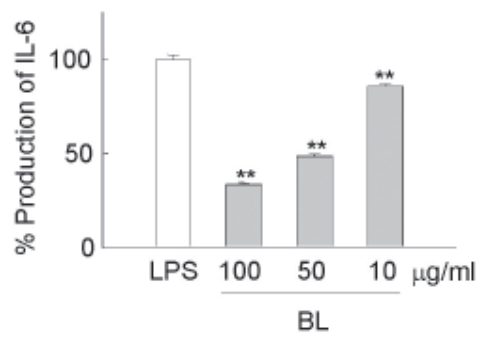

(b)

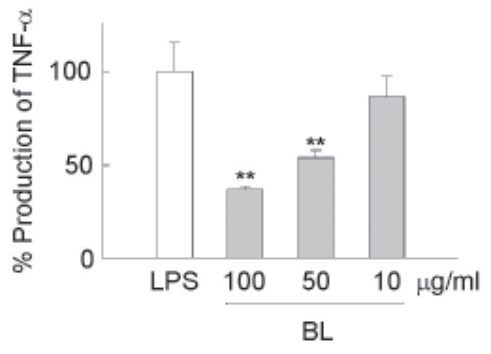

(d)
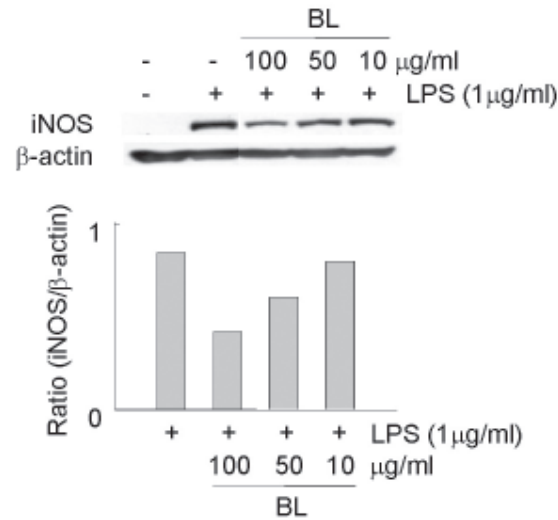

Fig. 2. Effects of BL on NO, TNF- $\alpha$ and IL-6 production from LPS-treated $\mathrm{MH}-\mathrm{S}$ cells (a) Inhibition of NO production, (b) Inhibition of TNF-a production, (c) Inhibition of IL-6 production, (d) Western blotting analysis. ${ }^{* *}: p<0.01$, Significantly different from the LPStreated control group $(n=3)$.
Table 1. Inhibition of CGN-induced pleurisy in rats (5 h)

\begin{tabular}{lccl}
\hline Compounds & $\begin{array}{c}\text { Dose } \\
(\mathrm{mg} / \mathrm{kg})\end{array}$ & $\begin{array}{c}\text { Exudate } \\
\text { volume }(\mathrm{ml})\end{array}$ & $\begin{array}{c}\text { Total cell } \\
\text { number }\left(\times 10^{7}\right)\end{array}$ \\
\hline Vehicle & - & $5.20 \pm 0.05^{\mathrm{a}}(-)^{\mathrm{b}}$ & $0.63 \pm 0.01(-)$ \\
CGN-treated & - & $7.0 \pm 0.12(-)$ & $9.85 \pm 0.83(-)$ \\
Indomethacin & 20 & $6.38 \pm 0.06^{\mathrm{c}}(34.5)$ & $6.20 \pm 0.78^{\mathrm{d}}(39.6)$ \\
$\mathrm{BL}$ & 200 & $6.83 \pm 0.17(9.4)$ & $7.33 \pm 0.18^{\mathrm{c}}(27.3)$ \\
& 400 & $6.40 \pm 0.07(33.3)$ & $6.97 \pm 1.04^{\mathrm{d}}(31.2)$ \\
\hline
\end{tabular}

All compounds dissolved in DMSO were administered orally. ${ }^{a} \mathrm{n}=5$ (arithmetic mean $\pm \mathrm{SD}$ ), ${ }^{\mathrm{b}} \%$ Inhibition based on the formula: $1-[($ Test-vehicle control)/(CGN-treated-vehicle control $) \times 100]$, ${ }^{\mathrm{C}} p<0.05,{ }^{\mathrm{d}} p<0.01$. Significantly different from the CGN-treated control group.

production at the same concentration ranges (Fig. $2 \mathrm{~b}$ and 2c), with $\mathrm{IC}_{50}$ values of 61.7 and $48.4 \mu \mathrm{g} / \mathrm{ml}$, respectively. To elucidate the inhibitory mechanism of iNOS-induced NO production, Western blotting analysis was carried out. As shown in Fig. 2d, BL clearly inhibited iNOS induction in LPS-treated $\mathrm{MH}-\mathrm{S}$ cells, indicating that the NO inhibitory activity of BL may be mediated, at least in part, by iNOS down-regulation.

\section{In vivo study}

To elucidate the in vivo activity against animal models of lung inflammation, $5 \mathrm{~h}$ and $24 \mathrm{~h}$ CGN-induced pleurisy tests were employed. Injection of CGN into the pleural cavity resulted in the development of pleurisy as determined by increased exudate volume and recruitment of inflammatory cells including neutrophils and macrophages; neutrophils are the major cells recruited in the early time while macrophages are the
Table 2. Inhibition of CGN-induced pleurisy in rats (24 h)

\begin{tabular}{lccc}
\hline Compounds & $\begin{array}{c}\text { Dose } \\
(\mathrm{mg} / \mathrm{kg})\end{array}$ & $\begin{array}{c}\text { Exudate } \\
\text { volume }(\mathrm{ml})\end{array}$ & $\begin{array}{c}\text { Total cell } \\
\text { number }\left(\times 10^{7}\right)\end{array}$ \\
\hline Experiment 1 & & & \\
Vehicle & - & $5.40 \pm 0.24^{\mathrm{a}}(-)^{\mathrm{b}}$ & $0.28 \pm 0.30(-)$ \\
CGN-treated & - & $6.26 \pm 0.28(-)$ & $15.66 \pm 4.70(-)$ \\
Prednisolone & 20 & $5.87 \pm 0.21^{\mathrm{c}}(45.3)$ & $6.37 \pm 0.71^{\mathrm{d}}(60.4)$ \\
Indomethacin & 20 & $6.60 \pm 0.99(-53.5)$ & $9.37 \pm 1.20^{\mathrm{c}}(40.9)$ \\
BL & 200 & $6.06 \pm 0.17(23.3)$ & $13.50 \pm 2.97(14.0)$ \\
& 400 & $5.94 \pm 0.63(37.2)$ & $10.26 \pm 6.83(35.1)$ \\
Experiment 2 & & & \\
Vehicle & - & $5.50 \pm 0.08(-)$ & $0.18 \pm 0.21(-)$ \\
CGN-treated & - & $6.64 \pm 0.55(-)$ & $17.44 \pm 1.18(-)$ \\
Zileuton & 50 & $6.52 \pm 0.42(10.5)$ & $13.48 \pm 6.49(23.0)$ \\
BL & 400 & $6.44 \pm 0.21(17.5)$ & $12.68 \pm 1.84^{\mathrm{d}}(2.76)$ \\
\hline
\end{tabular}

All compounds dissolved in DMSO were administered orally. ${ }^{a} n=5$ (arithmetic mean $\pm S D$ ), ${ }^{b} \%$ Inhibition based on the formula: $1-[($ Test-vehicle control]/(CGN-treated-vehicle control) $\times 100]$. ${ }^{\mathrm{c}} p<0.05,{ }^{\mathrm{d}} p<0.01$. Significantly different from the CGN--treated control group.

major cells recruited in the later time ( $24 \mathrm{~h}$ ) of CGN injection (Tomlinson et al., 1994; Willis et al., 1996). As expected, the exudate volumes of the pleural cavity increased and the cells in the exudates drastically increased in the $5 \mathrm{~h}$ model (acute lung inflammation) (Table 1). Under these conditions, BL (400 $\mathrm{mg} / \mathrm{kg}$ ) administered orally led to a considerable reduction in the exudate volume and blocked the recruitment of inflammatory cells. Indomethacin $(20 \mathrm{mg} / \mathrm{kg})$ used as a reference drug 
also inhibited both parameters, showing slightly higher activity than BL.

Table 2 shows the results of $24 \mathrm{~h}$ CGN-induced pleurisy (subacute lung inflammation). BL (200-400 mg/kg) reduced the exudate volume and cell numbers in the exudates. Specifically, BL induced a reduction of 37.2 and $35.1 \%$ against these two parameters when administered at $400 \mathrm{mg} / \mathrm{kg}$ (experiment 1). Prednisolone used as a reference drug strongly reduced the exudate volume and cell numbers, while indomethacin reduced the total cell numbers but increased the exudate volume. In comparison, zileuton (5-LOX inhibitor) showed some inhibitory action at $50 \mathrm{mg} / \mathrm{mg}$ when administered orally, showing weaker inhibitory activity than BL $(400 \mathrm{mg} / \mathrm{kg}$ ) (experiment 2).

Bronchitis as an animal model was induced by LPS instil- lation in rats. When LPS was directly instilled intratracheally, bronchitis characterized by inflammatory cell infiltration was produced (Fig. 3a). Under these conditions, BL (200-400 mg/ $\mathrm{kg})$ significantly reduced cell numbers in BALF $(41.2 \%$ and $66.7 \%$ reduction, respectively). The reference drug, montelukast $(30 \mathrm{mg} / \mathrm{kg}$, LT receptor antagonist), also reduced cell numbers $(26.9 \%)$, but was weaker than BL. Moreover, IL-1 $\beta$ and COX-2 expressed in lung tissue was reduced by $B L$ treatment when measured by RT-PCR analysis (Fig. 3b). Montelukast weakly reduced IL-1 $\beta$ and COX-2 expression. However, IL-6 and TNF- $\alpha$ genes were not detected in control or LPS instilled lung tissue (data not shown). Upon histological observation, a strong reduction of inflammatory response in the lung was observed in the BL-treated group $(400 \mathrm{mg} / \mathrm{kg})$ as well as the montelukast-treated group (Fig. 3c). (a)

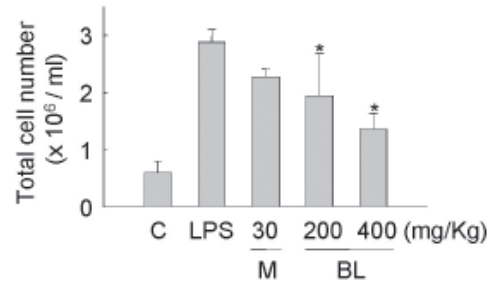

(b)

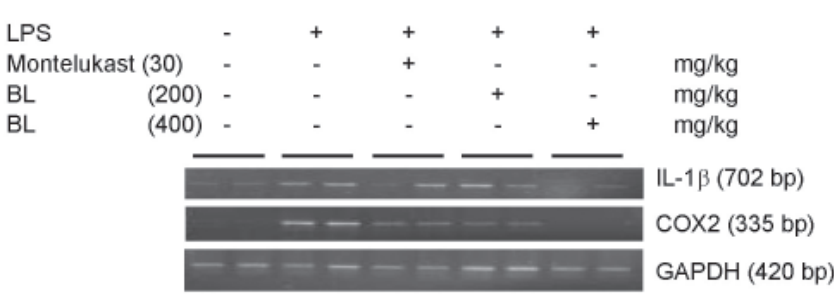

(c)

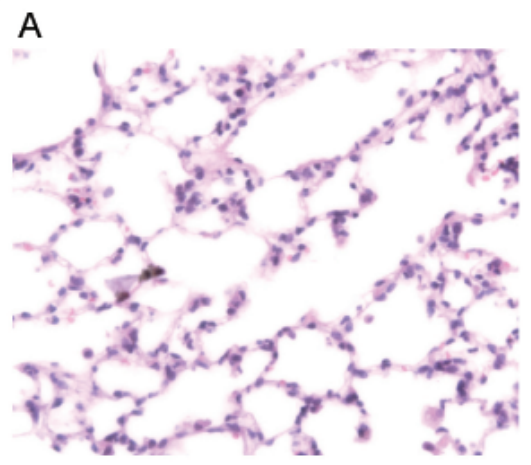

B

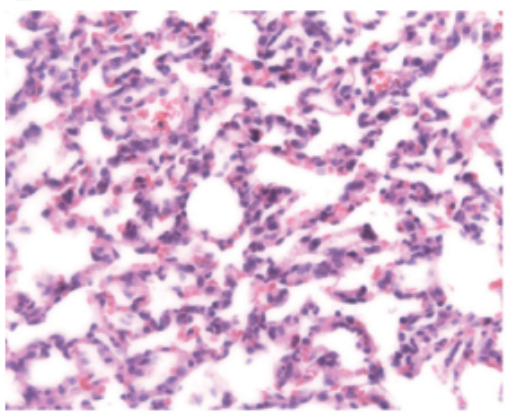

C
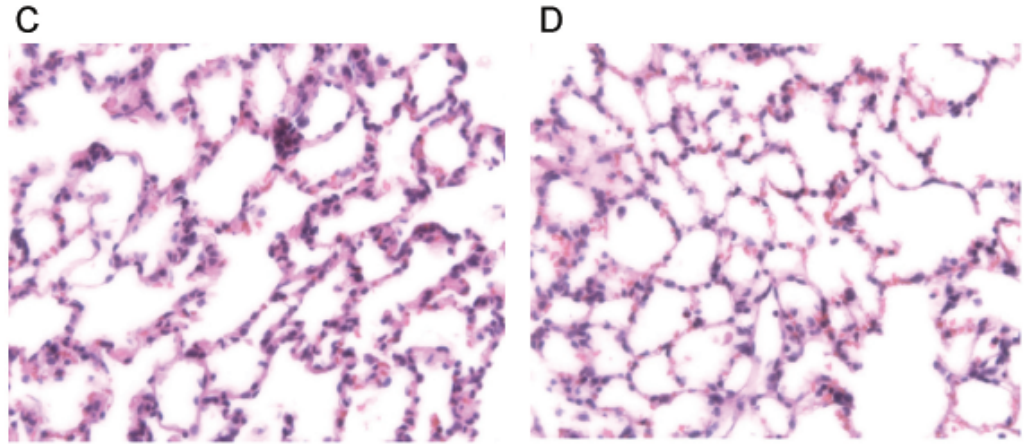

Fig. 3. Effects of BL on bronchitis induced by LPS instillation in rats. (a) Inhibition of cell infiltration, All compounds dissolved in DMSO were administered orally. The volume of BALF collected was approximately $0.15 \mathrm{ml}$ in all groups. Inhibition (\%) was calculated based on the formula: $1-\left[(\right.$ test-vehicle control)/(LPS-instilled-vehicle control) $\times 100]$. ${ }^{*} p<0.05$, significantly different from the LPS-instilled control group ( $\mathrm{n}=3$ ). (b) RT-PCR analysis of IL-1 $\beta$, (c) Histology, H\&E staining ( $\times 400)$. Note: Saline-treated control group (A) showed normal appearance. In LPSinstilled airway, airway inflammation, mucous cell hyperplasia and inflammation-related cell recruitment were observed (B), while all these responses were markedly reduced in the montelukast-treated $(30 \mathrm{mg} / \mathrm{kg})(\mathrm{C})$ and BL-treated lungs $(400 \mathrm{mg} / \mathrm{kg})(\mathrm{D})$. 


\section{DISCUSSION}

The present investigation clearly demonstrated that $\mathrm{BL}$ possesses significant anti-inflammatory activity against in vitro and in vivo animal models of lung inflammation, especially bronchitis. BL showed anti-inflammatory activity comparable to currently used drugs. This study presents strong scientific data supporting the potential for the use of $B L$ to treat human bronchitis.

Several prenylated flavonoids including papyriflavonol A and broussochalcone A were successfully isolated from the root barks of $B$. papyrifera as major constituents (Son et al., 2001). Among these, papyriflavonol $A$ is a relatively specific 5-LOX inhibitor (Chi et al., 2001b). Papyriflavonol A has also been found to inhibit allergic responses in vivo (Kwak et al., 2003). Because 5-LOX inhibitors have the potential to treat bronchial asthma as well as bronchitis, BL is thought to inhibit lung inflammation. In addition, broussochalcone A possesses iNOS down-regulating activity (Cheng et al., 2001). Furthermore, $L$. japonica is a well-known anti-inflammatory drug (Lee et al., 1998). This plant material is widely used to treat respiratory inflammation in Korea. Iridoids such as loganin have been isolated from these plant materials as major constituents. These compounds have also been reported to show anti-inflammatory activity (Lee et al., 1995). All of this background information led us to examine the inhibitory activity of BL against lung inflammation, and the results of the present investigation demonstrated that $\mathrm{BL}$ is effective for the treatment of animal models of lung inflammation at doses of $200-400 \mathrm{mg} / \mathrm{kg}$.

Our previous study (Jin et al., 2010) showed that BL inhibits 5-LOX and down-regulates iNOS. In the present investigation, in vitro study demonstrated that BL inhibited NO, TNF- $\alpha$ and IL- 6 production by alveolar macrophages and that the NO inhibitory action of BL was mediated in part by iNOS downregulation. These results, in combination with the previous findings, may indicate that BL possesses multiple anti-inflammatory action mechanisms; 5-LOX inhibition, down-regulation of proinflammatory enzymes such as iNOS and inhibition of the production of inflammatory cytokines including TNF- $\alpha$, IL$1 \beta$ and IL-6. All these action mechanisms may contribute to the in vivo anti-inflammatory activity of BL.

One biomarker of inflammatory response is inflammationrelated cell recruitment in the affected lesion. Although we did not differentially count the cell types, BL clearly inhibited infiltration of inflammatory cells in $5 \mathrm{~h}$ and $24 \mathrm{~h}$ CGN-induced pleurisy. These results may indicate that $\mathrm{BL}$ considerably inhibits lung inflammation of the pleural cavity, regardless of whether it is in the acute or subacute state. In addition, BL reduced cell numbers of BALF in a model of bronchitis. Since more than $90 \%$ of the cells in BALF were shown to be neutrophils (Starcher and Williams, 1989), BL is believed to reduce neutrophil infiltration in bronchitis induced by LPS instillation.

In the present investigation, we used indomethacin (COX inhibitor), prednisolone (steroidal anti-inflammatory drug), zileuton (5-LOX inhibitor) and montelukast (LT receptor antagonist) as the reference drugs depending on the in vivo experiments employed. In acute CGN-pleurisy (5 h), indomethacin strongly inhibited inflammatory responses based on cell numbers and pleurisy volume. Conversely, indomethacin increased the exudate volume in subacute CGN-pleurisy (24 h), while the 5-LOX inhibitors, zileuton and BL, inhibited this response. These results are well matched with the previous findings that 5-LOX is important to provoke inflammatory response in CGN-induced pleurisy (Cuzzocrea et al., 2003) and 5-LOX inhibitors are active on this animal model (Batt, 1992). In contrast, indomethacin inhibits COXs; thus, a considerable amount of arachidonic acid may be converted to LTs by 5-LOX, leading to an increase in the exudate volume in the $24 \mathrm{~h}$ model. Montelukast $(30 \mathrm{mg} / \mathrm{kg}$ ) showed inhibitory activity against bronchitis induced by LPS instillation, being less active than $\mathrm{BL}(400 \mathrm{mg} / \mathrm{kg})$ for blocking cell recruitment. In addition, montelukast clearly inhibited IL-1 $\beta$ and COX-2 m-RNA production and alleviated the lung inflammation shown by histological observation. These results are well correlated with the fact that LT receptor antagonist is effective for treating allergic asthma and bronchitis (Jeffery, 2001). When compared with the pharmacological actions of the reference drugs, BL showed broad inhibitory activity against these animal models, pleural cavity inflammation and bronchitis. Therefore, the results of the present study strongly suggest that BL has the potential for treatment of human lung inflammation as well as bronchitis.

In conclusion, the phytoformula, BL (mixture of B. papyrifera and $L$. japonica), showed in vitro and in vivo anti-inflammatory activity. BL exerted significant inhibitory activity in animal models of lung inflammation and against bronchitis. Moreover, BL has multiple action mechanisms. Specifically, it inhibits 5-LOX, down-regulates proinflammatory enzymes such as iNOS and inhibits the production of inflammatory cytokines such as TNF$\alpha$ and IL-6. All of these action mechanisms may participate in the in vivo action of BL. Taken together, these findings indicate that $\mathrm{BL}$ has the potential for use in the treatment of human bronchitis.

\section{ACKNOWLEDGMENTS}

This investigation was financially supported from Ministry of Knowledge Economy (Korea) (No. 70006104, 2009-2010), Korea Institute for Advancement of Technology (KIAT) and post BK-21 project from the Ministry of Education (Korea) and greatly acknowledged. The authors would like to thank Pharmacal Research Institute and Central Laboratory (KNU) for the use of bioassay facilities.

\section{REFERENCES}

Batt, D. G. (1992). 5-Lipoxygenase inhibitors and their anti-inflammatory activities. Prog. Med. Chem. 29, 1-63.

Cheng, Z. J., Lin, C. N., Hwang, T. L. and Teng, C. M. (2001). Broussochalcone $A$, a potent antioxidant and effective suppressor of inducible nitric oxide synthase in lipopolysaccharide-activated macrophages. Biochem. Pharmacol. 61, 939-946.

Chi, Y. S., Cheon, B. S. and Kim, H. P. (2001a). Effect of wogonin, a plant flavone from Scutellaria radix, on the suppression of cyclooxygenase and the induction of inducible nitric oxide synthase in lipopolysaccharide-treated RAW 264.7 cells. Biochem. Pharmacol. 61, 1195-1203.

Chi, Y. S., Jong, H. G., Son, K. H., Chang, H. W., Kang, S. S. and Kim, H. P. (2001b). Effects of naturally occurring prenylated flavonoids on arachidonic acid metabolizing enzymes: Cyclooxygenases and lipoxygenases. Biochem. Pharmacol. 62, 1185-1191.

Cuzzocrea, S., Rossi, A., Serraino, I., Mazzon, E., Di Paola, R., Dugo, L., Genovese, T., Calabro, B., Caputi, A. P. and Sautebin, L. (2003). 5-Lipoxygenase knockout mice exhibit a resistance to pleurisy and 
lung injury caused by carrageenan. J. Leukoc. Biol. 73, 739-746.

Editorial Committee of Zhong Hua Ben Cao of State Administration of Traditional Chinese Medicine of People's Republic of China. (1999) Zhong Hua Ben Cao vol. 2. Shanghai Science and Technology Publishing Co.: Shanghai; 473-474.

Holsapplae, M. P. and Yim, G. K. (1984). Therapeutic reduction of ongoing carrageenin-induced inflammation by lipoxygenase, but not cyclooxygenase inhibitors. Inflammation 8, 223-230.

Jeffery, P. K. (2001). Remodeling in asthma and chronic obstructive lung disease. Am. J. Respir. Crit. Care Med. 164, S28-S38.

Jin, J. H., Lim, H., Kwon, S. Y., Son, K. H. and Kim, H. P. (2010). Anti-inflammatory activity of the total flavonoid fraction from Broussonetia papyrifera in combination with Lonicera japonica. Biomol. Therap. 18, 197-204.

Kawai, H., Kutoyanagi, M. and Ueno, A. (1988). Iridoid glucosides from Lonicera japonica Thunb. Chem. Pharm. Bull. 36, 3664-3666.

Kwak, W. J., Moon, T. C., Lin, C. X., Rhyn, H. G., Jung, H., Lee, E., Kwon, D. Y., Son, K. H., Kim, H. P., Kang, S. S., Murakami, M., Kudo, I. and Chang, H. W. (2003). Papyriflavonol A from Broussonetia papyrifera inhibits the passive cutaneous anaphylaxic reaction and has a secretory phospholipase A2 inhibitory activity. Biol. Pharm. Bull. 26, 299-302.

Lee, S. J., Shin, E. J., Son, K. H., Chang, H. W., Kang, S. S. and Kim, H. P. (1995). Anti-inflammatory activity of the major constituents of Lonicera japonica. Arch. Pharm. Res. 18, 133-135.

Lee, S. J., Son, K. H., Chang, H. W., Kang, S. S. and Kim, H. P. (1998). Anti-inflammatory activity of Lonicera japonica. Phytother. Res. 12 445-447.

Lin, L. W., Chen, H. Y., Wu, C. R., Liao, P. M., Lin, Y. T., Hsieh, M. T. and Ching, $H$. (2008). Comparison with various parts of Broussonetia papyrifera as to the antinociceptive and anti-inflammatory activities in rodents. Biosci. Biotechnol. Biochem. 72, 2377-2384.
Mossman, T. (1983). Rapid colorimetric assay for cellular growth and survival: application to proliferation and cytotoxic assays. J. Immunol. Methods 65, 55-63.

Qian, Z. M., Li, H. J., Li, P., Chen, J. and Tang, D. (2007). Simultaneous quantification of seven bioactive components in Caulis Lonicera japonicae by high performance liquid chromatography. Biomed. Chromatogr. 21, 649-654.

Ryu, K. H., Rhee, H. I., Kim, J. H., Yoo, H., Lee, B. Y., Um, K. A., Kim, K., Noh, J. Y., Lim, K. M. and Chung, J. H. (2010). Anti-inflammatory and analgesic activities of SKLJI, a highly purified and injectable herbal extract of Lonicera japonica. Biosci. Biotechnol. Biochem. 74, 2022-2028.

Schrier, D. J., Lesch, M. E., Wright, C. D. and Gilbertson, R. B. (1990) The anti-inflammatory effects of adenosine receptor agonists on the carrageenan-induced pleural inflammatory response in rats. $J$. Immunol. 145, 1874-1879.

Shougakukan. (1985) The dictionary of Chinese drugs vol. 3. Shanghai Science and Technologic Publishers and Shougakukan: Tokyo; 2027-2029.

Son, K. H., Kwon, S. J., Chang, H. W., Kim, H. P. and Kang, S. S. (2001). Papyriflavonol A, a new prenylated flavonoid from Broussonetia papyrifera. Fitoterapia 72, 456-458.

Starcher, B. and Williams, I. (1989). A method for intratracheal instillation of endotoxin into the lungs of mice. Laboratory Animals 23, 234-240.

Tomlinson, A., Appleton, I., Moore, A. R., Gilroy, D. W., Willis, D., Michell, J. A. and Willoughby, D. A. (1994). Cyclo-oxygenase and nitric oxide synthase isoforms in rat carrageenin-induced pleurisy. Brit. J. Pharmacol. 113, 693-698

Willis, D., Moore, A. R., Frederick, R. and Willoughby, D. A. (1996). Heme oxygenase: a novel target for the modulation of the inflammatory response. Nature Med. 2, 87-90. 